Title: When Cheaper is Better: Fee Determination in the Market for Equity Mutual Funds Authors: Javier Gil-Bazo and Pablo Ruiz-Verdú ${ }^{1}$

\begin{abstract}
In this paper, we develop a model of the market for equity mutual funds that captures three key characteristics of this market. First, there is competition among funds. Second, fund managers' ability is not observed by investors before making their investment decisions. And third, some investors do not make optimal use of all available information. The main results of the paper are that 1) price competition is compatible with positive mark-ups in equilibrium; and 2) worse-performing funds set fees that are greater or equal than those set by better-performing funds. These predictions are supported by available empirical evidence.
\end{abstract}

JEL classification codes: L13, L15, G23, D80.

Keywords: mutual fund fees, mutual fund performance, product quality, asymmetric information, bounded rationality.

\footnotetext{
${ }^{1}$ Corresponding author: Pablo Ruiz-Verdú, Universidad Carlos III de Madrid, Department of Business Administration. Calle Madrid, 126. 28903 - Getafe, Madrid - Spain. E-mail: pablo.ruiz@uc3m.es.
} 


\title{
When Cheaper is Better: Fee Determination in the Market for Equity Mutual Funds
}

\begin{abstract}
In this paper, we develop a model of the market for equity mutual funds that captures three key characteristics of this market. First, there is competition among funds. Second, fund managers' ability is not observed by investors before making their investment decisions. And third, some investors do not make optimal use of all available information. The main results of the paper are that 1) price competition is compatible with positive mark-ups in equilibrium; and 2) worse-performing funds set fees that are greater or equal than those set by better-performing funds. These predictions are supported by available empirical evidence.
\end{abstract}

JEL classification codes: L13, L15, G23, D80.

Keywords: mutual fund fees, mutual fund performance, product quality, asymmetric information, bounded rationality. 


\section{Introduction}

In 2003, total mutual fund assets in the U.S. were worth 7.4 trillion dollars and constituted an estimated 18.4 percent of the total financial wealth of U.S. households (Investment Company Institute, 2004). The increasing reliance of American investors on mutual funds has raised concerns among industry commentators and regulators alike about the extent of competition in the industry and, in particular, about the level of fees that mutual funds charge investors for their services. ${ }^{1}$ These concerns have prompted regulators to commission reports (Securities and Exchange Commission, 2000; General Accounting Office, 2000) to analyze the evolution and determinants of mutual fund fees. More recently, a series of scandals, ${ }^{2}$ have triggered regulatory initiatives that, among other things, strengthen mutual fund fee disclosure requirements so as to promote price competition in the industry. ${ }^{3}$ Underlying this debate is a long overdue question: How are fees determined in the mutual fund market? To address this question, in this paper, we develop a model of the market for equity mutual funds.

One of the main concerns fueling the debate over mutual fund fees, and a key motivation for the regulatory changes requiring improved fee disclosure, has been the degree to which investors are aware of the fees associated with fund investments and their impact on the return of those investments. A survey by the SEC and the Office of the Comptroller of the Currency (Alexander et al., 1997) reports that fewer than one in six fund investors understand that higher fund expenses-which are deducted from the fund's assets and mostly consist of management fees-lead to lower returns. The survey also documents that investors are not familiar with the level of fees they are paying for mutual fund services (not even $20 \%$ of the respondents was able to give an estimate of the expenses paid for their largest mutual fund) and reveals other gaps in financial literacy. Similar results have been obtained in studies by Capon et al. (1996) and Wilcox (2003). More recently, a study by Barber et

\footnotetext{
${ }^{1}$ For example, in a recent article about the topic in The Economist, one could read: "Retail investors [...] have seen precious little competition on prices. Even for wretched performance, reductions in fees have been all too rare." (The Economist, 2004).

${ }^{2}$ See, for instance, Dwyer, Borrus and Young (2003) for an account of these scandals.

${ }^{3}$ The Securities and Exchange Commission has issued a rule establishing stronger disclosure requirements for mutual funds (Securities and Exchange Commission, 2004). The "Mutual Funds Integrity and Fee Transparency Act of 2003", which imposes strict governance and disclosure requirements, passed the U.S. House overwhelmingly in November, 2003.
} 
al. (2005) has provided further evidence of investors' difficulties understanding the effects of mutual fund fees. In light of these findings, it is our view that a satisfactory model of the mutual fund market should account for the presence of a significant fraction of investors who make less than optimal use of the information available when making their investment decisions.

The model developed in this paper has three main ingredients, which, we believe, characterize the market for equity mutual funds. In the U.S., investors can choose from a large pool of mutual funds, even for relatively narrowly defined investment categories. Therefore, the first ingredient of our model is competition among-possibly many-funds for investors' money. This ingredient is key, because we would like to know whether existing concerns about the level of fees charged by mutual funds can still be warranted in the presence of mutual fund competition. Since our main focus is the market for equity mutual funds, the second ingredient is quality uncertainty: different fund managers have different abilities to generate returns, but those abilities are not known ex ante by investors. Even though in actual markets, funds' past returns could be used as a signal of performance, this signal is, at best, highly noisy. Therefore, the assumption that quality is not observable appears as a reasonable first approximation. The third ingredient is the presence of a fraction of investors who do not make optimal use of all available information when making their investment decisions. We label these investors unsophisticated.

The model enables us to address several questions: 1) Should we expect price competition among funds to bring equilibrium profits down to zero? 2) Will high-quality funds drive low-quality funds out of the market? If low-quality funds manage to survive in equilibrium, 3) will high-quality funds charge higher fees, so that, in equilibrium, all investors earn the same expected net returns? If, on the contrary, net returns differ across funds, 4) which funds will be more likely to overcharge investors: high- or low-quality funds? These questions lie at the heart of the debate over the extent of competition in the mutual fund industry and are of key importance in evaluating proposed regulatory changes. The model shows that, in equilibrium: 1) funds earn positive profits; 2) high- and low-quality funds coexist; 3 ) high-quality funds never charge higher fees and may charge lower fees; and that, as a consequence, 4) low-quality funds greatly overcharge investors. 
The intuition behind these, perhaps surprising, results is as follows. In the mutual fund market, the revenues earned by a mutual fund are the product of its fee and the fund asset value. Therefore, in a setting in which quality is unobservable, high-quality funds-namely those that deliver a higher value-may be able to differentiate themselves by setting low fees. If those fees are low enough, low-quality funds would not break even by imitating them. Unable to compete for the sophisticated segment of the market, low-quality funds would focus instead on extracting rents from unsophisticated investors. It should be noted that, although the presence of unsophisticated investors is necessary to obtain this sort of price differentiation in equilibrium, it is not sufficient. The model's results follow from the interaction between asymmetric information and the existence of those investors.

The assumption that fund quality is completely unobservable can seem unrealistic if, as indicated by the empirical evidence, past mutual fund returns have some value as predictors of future performance. The complexity involved in evaluating and forecasting mutual fund performance, however, suggests that past returns are only a noisy signal of future performance. The assumption of asymmetric information is, therefore, still reasonable given that managers possess skills, technology and access to return-relevant data that investors lack. In section 4, we investigate the effects of allowing investors to observe a signal of fund quality prior to making their purchase decision. Our results suggests that, as long as the signal is only imperfectly correlated with fund performance, there are still separating equilibria like the ones described above.

The available empirical evidence is fully consistent with our model: funds not only fail to adjust fees so as to offset differences in before-fee returns, but, on the contrary, funds of lower quality charge higher fees. Elton et al. (1993), for instance, document significant differences in after-fee returns across mutual funds and show that funds that charge higher fees deliver significantly lower before-fee returns. Additional evidence provided by Gruber (1996), Carhart (1997), Harless and Peterson (1998), and Chevalier and Ellison (1999) has consistently confirmed the power of high fees to predict underperformance. Surprisingly, this anomalous pattern in the data has not been explained by any previous formal model of the mutual fund industry.

Although there exists a relatively large theoretical literature, initiated by Bhattacharya 
and Pfleiderer (1985), that aims at characterizing the optimal compensation contract in a delegated portfolio management problem, ${ }^{4}$ few studies have analyzed fund fees as the outcome of the strategic interaction of competing mutual funds. Recently, Hortacsu and Syverson (2004) have developed a search model of the market for S\&P 500 index funds. In contrast to our paper, however, they analyze a sector in which financial performance differences across funds are relatively small and thus focus on non-portfolio fund differentiation and search frictions as potential sources of fee dispersion. In another recent paper, Berk and Green (2004) have proposed a model of the mutual fund market with no informational asymmetries or search frictions. The goal of their model is to explain why money may rationally follow past good performance even when past performance is not a strong predictor of future performance. The paper is, however, silent about the determinants of the observed distribution of fees. Das and Sundaram (2002) and Metrick and Zeckhauser (1999) have analyzed fee setting in a duopoly context with asymmetric information about fund quality. While Das and Sundaram (2002) compare the performance of two types of incentive schemes for fund managers in such a context, the goal of Metrick and Zeckhauser (1999) is to explain why high- and low-quality producers may charge the same price in certain markets (including the mutual fund market), and is, thus, closely related to ours. We discuss their results in section 2. In another related paper, Nanda et al. (2000) have developed a model where mutual fund managers of observable quality bear the cost of stochastic investment redemptions, and therefore wish to attract investors who are less likely to experience liquidity needs. In equilibrium, more skilled fund managers impose exit fees and cater to investors with lower liquidity needs, while less skilled managers become liquidity providers. Finally, Christoffersen and Musto (2002) have recently explored empirically the effect of investors' performance sensitivity on fund fees.

Our paper is also related to the more general literature on the role of prices as signals of quality. In this literature, high prices generally signal high quality (e.g., Bagwell and Riordan, 1991), although in some contexts involving repeated purchases, it has been shown that low introductory prices can be used as signals of quality (Schmalensee, 1978). This set of work, however, has mostly focused on the case of a single seller of unknown quality.

\footnotetext{
${ }^{4}$ See, e.g., Palomino and Prat (2003) for a recent contribution.
} 
Only recently, Fluet and Garella (2002) and Hertzendorf and Overgaard (2001) have studied price and advertising signaling for the case of a duopoly. In their models, high-quality firms charge higher prices in any separating equilibrium. Of related interest is a recent working paper by Gabaix and Laibson (2003), in which the authors argue that product-or pricingcomplexity can allow firms to obtain positive mark-ups in equilibrium and that increases in competition may actually exacerbate the problem.

The rest of the paper is organized as follows: Section 2 presents the benchmark model; Section 3 extends the model to include unsophisticated investors and section 4 assesses the consequences of the existence of a noisy signal of fund quality; Section 5 discusses the available evidence on the relationship between performance and fees, and, finally, section 6 concludes.

\section{A Model of Fee Determination in the Market for Mutual Funds}

Consider a simple setting in which there is a continuum of investors of mass one who have one dollar to invest, and $N$ mutual fund managers. These managers can be of two types depending on their ability: good $(g)$ and bad $(b)$. G-managers earn gross expected return $R_{g}$, and b-managers $R_{b}$, where $R_{g}>R_{b}$, and $R_{g}>1$. Returns are assumed to be independent of fees, so we can abstract from moral hazard problems. The ex ante distribution of types is given by the probability $p$ that a manager is good. Once the types are realized, fund managers observe their quality but not the quality of their rivals and decide what fraction $e$ of the fund's final asset value to charge to investors. The assumption that fees are determined as a fraction of asset value is made to reflect actual practice in the mutual fund industry. In section 5, we discuss in greater detail the different fees paid by mutual fund investors.

Investors do not observe quality, so they decide where to invest on the basis of the prior distribution and the fees charged by the different funds. As argued in the introduction, even if fund quality could be inferred from different sources of information, such as past returns, evaluating and forecasting mutual fund performance is a very complex and costly task for retail investors. Fund managers, on the other hand, possess skills, technology and 
access to data about their portfolios and organization that investors lack. We therefore believe that fund managers can be expected to be better informed about their own ability to generate returns than investors. We discuss this issue in greater detail in section 4, where we allow investors to be imperfectly informed about fund quality.

We will assume that a fraction $\gamma$ of all investors are unsophisticated, in the sense that they do not make optimal use of all available information. Since we will first analyze the case with no unsophisticated investors, we postpone the discussion of the precise form in which these investors behave until they are introduced in section 3 .

The costs of managing the fund are $c w$, where $w$ is the amount of money managed by the fund manager. It is assumed that costs are low enough to make it profitable for g-funds to operate if their type is known. We assume that all market participants are risk-neutral, ${ }^{5}$ and that the only alternative investment is a risk-free asset paying a zero interest rate. Therefore, the maximum fee a fund of type k can charge if its type is known is such that the net return for investors is equal to one: $R_{k}(1-e)=1$, that is $e=\frac{R_{k}-1}{R_{k}}$. Therefore, the assumption that g-funds may profitably operate if their type is known can be expressed as follows:

\section{Assumption 1}

$$
\frac{R_{g}-1}{R_{g}}>\frac{c}{R_{g}}
$$

where the right-hand side of the inequality is the break-even fee for g-funds.

We also assume that, given $c$, b-funds may find it profitable to operate for some fee less than one hundred percent:

Assumption $2 R_{b}>c$.

\footnotetext{
${ }^{5}$ The risk-neutrality assumption enables us to focus on a single mutual fund characteristic, expected return, so rational investors will always choose the fund with the highest (after-expense) expected return. We could alternatively drop risk neutrality and replace expected return for a measure of mutual fund riskadjusted performance. A commonly used proxy for risk adjusted-performance is the fund's alpha, defined as the fund's expected return in excess of that implied by the Capital Asset Pricing Model (CAPM) or an Arbitrage Pricing Theory (APT) -type model. Under the CAPM assumptions, it can be shown that combining a fund with positive alpha with the market portfolio strictly improves the investor's risk-return trade-off. Under the APT assumptions, a strategy long in a fund with positive alpha and short in risk-free asset and in the factor-mimicking portfolios, is an arbitrage. Therefore, investors constrained in the amount of money they can invest in mutual funds, would optimally choose the mutual fund with the highest (afterexpense) alpha, regardless of their risk aversion. If all agents agree on the definition of alpha, then our model is unchanged.
} 
We denote by $e_{k}$ the fee charged by a manager of type $k$ as a proportion of the value of the fund at the end of the period and assume that there are no other fees. Therefore, the amount paid by an investor who invests $w$ dollars in a fund of type $k$ is $w e_{k} R_{k}$, and payoffs are $w\left(e_{k} R_{k}-c\right)$ for the manager and $w\left(1-e_{k}\right) R_{k}$ for the investor.

Finally, the timing of decisions is as follows. First, managers simultaneously set fees. Then investors decide where to invest. We make the assumption that, if several funds have the same net expected returns, investors allocate their wealth among them with equal probability.

\subsection{Benchmark Case: Complete Information}

Before solving the model, it is instructive to investigate the relationship between fund quality and fees when there are no unsophisticated investors and quality is observed both by competing funds and by investors. It is straightforward to show that, in this case, b-funds will be driven out of the market whenever there are g-funds:

Proposition 1 With complete information, there do not exist equilibria in which both fund types operate simultaneously.

Proof. First, note that for both types of funds to have a positive market share:

$$
\left(1-e_{b}\right) R_{b}=\left(1-e_{g}\right) R_{g}
$$

which implies that $e_{b}<e_{g}$.

With complete information the number of funds of each type is given and commonly known. We study first the case in which there is only one g-fund active and then the case in which there are at least two g-funds. So, suppose first that there is only one g-fund.

For b-funds to operate $e_{b} \geq \frac{c}{R_{b}}>\frac{c}{R_{g}}$, which implies that $e_{g}>\frac{c}{R_{g}}$. Therefore, if $e_{b} \geq \frac{c}{R_{b}}$, it would be profitable for the g-fund to lower $e_{g}$ slightly and attract the whole market. It follows that, in equilibrium, b-funds cannot operate. The g-fund will set the minimum fee that guarantees that b-funds do not want to enter, which is given by:

$$
\left(1-e_{g}\right) R_{g}=\left(1-\frac{c}{R_{b}}\right) R_{b}
$$


If there are several g-funds, the same argument applies for any $e_{g}>\frac{c}{R_{g}}$. The only possible equilibrium fee is $e_{g}=\frac{c}{R_{g}}<\frac{c}{R_{b}}$, so b-funds remain inactive.

Therefore, good and bad funds cannot coexist in equilibrium with complete information: whenever it is profitable for b-funds to operate, it is also profitable for g-funds to lower fees. ${ }^{6}$ As a result, b-funds are driven out of the market.

\subsection{Asymmetric Information}

We now investigate what happens when there is asymmetric information regarding funds' ability to generate returns. To understand the contribution of the model's different assumptions, we maintain the assumption that there are no unsophisticated investors. We use the Perfect Bayesian Equilibrium as our equilibrium concept and focus only on pure-strategy symmetric equilibria (i.e., equilibria in which all funds of the same type play the same pure strategy). To limit equilibrium multiplicity, we require investors' out-of-equilibrium beliefs to satisfy the property that they do not assign positive probability to managers setting fees that are certain to yield them a negative profit. That is, investors cannot assign a positive probability to a fund of type $k$ choosing a fee less than $\frac{c}{R_{k}}$. Therefore, throughout the paper, by equilibrium we will refer to a pure-strategy Perfect Bayesian Equilibrium satisfying this restriction on investors' beliefs.

First, note that in a separating equilibrium in which both types are ever active simultaneously, it has to be the case that net returns for investors are equal across types, since, otherwise, investors would not invest with the two types when both are available. Equality of net returns, in turn, implies that the expected market shares of g- and b-funds also have to be equal, ${ }^{7}$ since investors are indifferent between both types and, therefore, allocate the money across funds with equal probability. But this implies that, if $e_{g}>e_{b}$, it would be optimal for b-managers to imitate g-managers. On the other hand, if $e_{g}<e_{b}$, no rational investor that observes both fees would invest with a b-manager. Therefore:

Proposition 2 If all investors react optimally to differences in expected payoffs, there are

\footnotetext{
${ }^{6}$ In models of vertical differentiation (e.g., Shaked and Sutton, 1982), equilibria in which low- and highquality producers coexist-with the former charging lower prices-are possible if consumers display differences in their willingness to pay for quality. In the mutual fund industry, however, where the good provided by sellers is end-of-period dollars, one would expect that all consumers have the same willingness to pay for quality: nobody would pay more cents than anybody else for a dollar.

${ }^{7}$ The expectation is taken over the possible realizations of the number of b- and g-funds.
} 
no separating equilibria in which both fund-types operate simultaneously.

According to Proposition 2, we should observe no fee dispersion in equilibrium: for any realization of the number of b- and g-funds, all the funds with a positive market share must charge the same fees. Equilibria at which b- and g-funds are active simultaneously and the latter charge higher fees are not possible.

It is straightforward to show that, with asymmetric information, equilibria like the one obtained with complete information, in which only g-funds are active and make zero profits, are not possible. The reason is that any g-fund faces a positive probability of competing only against b-funds. Therefore, there exists a strategy that guarantees positive expected profits to g-funds: setting a fee greater than the break-even fee for g-funds $\left(\frac{c}{R_{g}}\right)$, but lower than the break-even fee for b-funds $\left(\frac{c}{R_{b}}\right)$. Such a fee guarantees positive profits if the fund is ever able to attract any money and, as long as it is not too high, ensures that the fund would attract investors' money at least when there are no competing g-funds. The fact that g-funds have a strategy that guarantees positive expected profits immediately rules out Bertrand-like equilibria, like the one that results from complete information. It is possible to show, though, that, for a broad range of parameter values, there are equilibria in which both types of funds are active, set the same fee and obtain positive profits. With complete information, equilibria with positive profits are not possible. If there is asymmetric information, however, undercutting other funds' fees can be interpreted by investors as a signal of low quality, so that, if investors are sufficiently pessimistic in their assessment of deviating funds, equilibria with positive profits can arise. ${ }^{8}$

We would like to note here that the existence of an equilibrium at which funds of different qualities set the same fee has already been proposed by Metrick and Zeckhauser (1999), although in a very different context. Metrick and Zeckhauser (1999) study a verticallydifferentiated duopoly characterized by sequential price setting (with good funds setting fees-front-end loads-before bad funds) and by investor heterogeneity along two dimensions: on the one hand, different investors value the "good" provided by mutual funds differently; and, on the other hand, some investors can observe quality, while others cannot. In this

\footnotetext{
${ }^{8}$ We omit the proof of the existence of this type of equilibrium, since it can be obtained as a special case of the pooling equilibria analyzed in the next section.
} 
context, an equilibrium in which both funds set the same price can arise when the qualities are similar enough. The reason is that competition for the investors who can observe quality is strong in this case. As a result, the good fund may find it optimal to set a fee low enough to force bad funds out of the informed segment of the market. It is important to note that, in their model, good funds attract more money than bad funds in a pooling equilibrium, since the latter do not get any money from informed investors. It is also worth noting that, in their model, there are also separating equilibria in which both funds are active and good funds charge higher fees. In our model, these equilibria are not possible.

\section{Unsophisticated Investors}

In the introduction, we argued that a satisfactory model of the mutual fund industry should account for the empirical evidence that a significant fraction of investors do not make optimal use of all available information when making their investment decisions. For example, in a survey conducted by Capon et al. (1996), more than $70 \%$ of respondents did not know whether their mutual funds invested mainly in domestic or international stocks, or whether they invested mainly in equity or fixed income. Especially notable is investors' ignorance of the fees charged by their mutual funds. In particular, a survey commissioned by the SEC and the Office of the Comptroller of the Currency (Alexander et al., 1997) shows that $81.2 \%$ of respondents could not give an estimate of the expenses of the largest fund they owned and, of those investors, only $43 \%$ claimed to have known their largest fund's expenses at the time they first invested in the fund. Investors' ignorance of management fees is consistent with the importance that they assign to these fees when determining their investment choices: Capon et al. (1996) report that the mean importance given by individual investors to management fees as a selection criterion is 2.28 in a scale from 1 to 6, and Wilcox (2003) finds similar results when inferring investors' selection criteria from actual choices. If investors weight any fees at all, they consider load fees and not management fees (Barber et al., 2005).

Investors' insensitivity to management fees may reflect the lack of salience of these fees (Barber et al., 2005): management fees are paid over time, are calculated as a fraction of the value of the investment, and are, therefore, hard to translate into (discounted) dollar 
terms. Further, since expenses are typically in the range of $1-2 \%$, some investors may underestimate the long run effects of apparently small differences in expenses or code as equal expenses with different long run effects. The problem of processability of information on mutual fund expense ratios is stressed by Cox and Payne (2005), who apply Slovic's (1972) concreteness principle to argue that investors tend to accept the information on fees in the format it is given, rather than expending cognitive effort to transform it, and, thus, provide a justification to the SEC's new rule requiring funds to to disclose expenses in dollar terms. However, Cox and Payne (2005) also argue that these disclosure requirements may not be sufficient and that management fees will be underweighted in decisions unless they are expressed relative to those of comparable funds.

The evidence, thus, shows that the behavior of a large fraction of investors is markedly different from that of the sophisticated investors we considered in the previous section, who not only knew the fees charged by all funds, but rightly understood in equilibrium the relation between fees and expected performance. In this section, in addition to sophisticated investors, we include a fraction of investors whose investment choices are largely unresponsive to fees. More specifically, we assume that the probability of an unsophisticated investor investing in a given mutual fund is the same for all funds and independent of the fee charged by the fund as long as that fee is below a threshold value $e_{U}$. This threshold reflects the fact that, even though investors may not be fully aware of the exact value of fees or of their implications for net returns when they lie within a reasonable range, they would detect fees that are conspicuously high. We take a conservative approach and assume that this threshold is relatively low and given by:

$$
\bar{R}\left(1-e_{U}\right)=1
$$

where $\bar{R}=p R_{g}+(1-p) R_{b}$ is the expected gross return. That is, unsophisticated investors invest only if the expected net return, given the distribution of fund types, is at least as high as that of the alternative asset. Arguably, this requirement demands too much sophistication from unsophisticated investors. As we discuss below, however, our results do not depend on the specific choice of $e_{U}$ and are consistent with both higher and lower values of this variable. Finally, we assume that unsophisticated investors do not infer any 
information about a fund's quality from the fee it charges. Again, we could somewhat relax this assumption. However, as we argue below, we do not think that doing this would increase the realism of our assumptions and would unnecessarily complicate the results.

To derive the market equilibrium when there is a fraction $\gamma$ of unsophisticated investors, note first that a reasoning similar to Proposition 2 still applies in this case: in equilibrium, b-managers and g-managers cannot both serve the sophisticated market segment and charge different fees. If $e_{g}>e_{b}$, b-managers would mimic g-managers' pricing strategy. If $e_{g}<e_{b}$, sophisticated investors would not invest in b-funds. Therefore, if the presence of unsophisticated investors allows for the existence of separating equilibria in which both fund types are active simultaneously, sophisticated investors must prefer one type of fund over the other. The possibility that b-funds offer a higher net return in equilibrium can be ruled out, since it is straightforward to show that there cannot exist separating equilibria in which g-funds serve only unsophisticated investors and b-funds serve sophisticated investors. Therefore, we investigate next whether there can exist separating equilibria in which both fund types are active simultaneously and in which b-funds serve only unsophisticated investors as long as there are competing g-funds. Obviously, for these equilibria to exist, b-funds must be able to at least break even by charging $e_{U}$, since, otherwise, they would never be active.

Assumption $3 e_{U}>\frac{c}{R_{b}}$.

The following conditions must hold at this type of equilibrium:

$$
\begin{aligned}
& w_{g}^{U}\left(R_{g} e_{g}-c\right) \geq w_{b}^{U}\left(R_{g} e_{b}-c\right) \\
& w_{b}^{U}\left(R_{b} e_{b}-c\right) \geq w_{g}^{U}\left(R_{b} e_{g}-c\right) \\
& w_{b}^{U}\left(R_{b} e_{b}-c\right) \geq 0,
\end{aligned}
$$

where $w_{k}^{U}$ is the wealth that a fund setting $e_{k}$ expects to obtain conditional on all other funds playing the equilibrium strategies. Note that $e_{g}<e_{b}$ implies that if b-funds serve any sophisticated investors at all, they will do so only when there are no g-funds in the market. Since all funds get the same share of unsophisticated investors' money, it follows that $w_{g}^{U}>w_{b}^{U}$. Note also that if $e_{g}<e_{b}, w_{g}^{U}>w_{b}^{U}$ must hold for condition (NIg) to be satisfied. 
The first two conditions above are no-imitation constraints for g- and b-funds, respectively, and the last condition is a participation constraint for b-funds. A participation constraint for g-funds is not necessary, because it is implied by (NIb) and (Pb). Note that, since $w_{g}^{U}>w_{b}^{U}$, condition (NIb) requires that $e_{g}<e_{b}$ : in this type of equilibrium, g-funds must set lower fees.

Fees also have to be low enough to convince both sophisticated and unsophisticated investors to participate:

$$
\begin{aligned}
& e_{g} \leq \frac{R_{g}-1}{R_{g}} \\
& e_{b} \leq e_{U}
\end{aligned}
$$

Finally, it cannot be profitable for b- or g-funds to deviate and set an out-of-equilibrium fee. To evaluate these deviations, we need to make assumptions about sophisticated investors' out-of-equilibrium beliefs. To prove the results below, we assume that sophisticated investors interpret any deviation from equilibrium as coming from a b-fund unless it yields negative profits for such a fund. These extreme beliefs are chosen to simplify the proofs and are not necessary. For our results to hold, all that is required is that sophisticated investors assign a sufficiently high probability to a deviator being of low quality. The next proposition shows that there are parameter values such that all the above conditions hold simultaneously and there are no profitable out-of-equilibrium deviations (all omitted proofs can be found in the appendix):

Proposition 3 There exist separating equilibria with unsophisticated investors at which:

1. b-funds serve unsophisticated investors only and charge $e_{b}^{*}=e_{U}$.

2. g-funds charge $e_{g}^{*}>\frac{c}{R_{b}}$ and serve both sophisticated and unsophisticated investors.

3. $e_{b}^{*}>e_{g}^{*}$.

Figures ??-?? show that separating equilibria of this sort can exist for reasonable parameter values. For each possible value of $\gamma$ (plotted along the x-axis), the figures graph the minimum and maximum values of $c$ (plotted along the y-axis) for which these equilibria can exist. 
The equilibria described in Proposition 3 are the only possible separating equilibria, but there may also exist pooling equilibria for certain parameter values. At these pooling equilibria, g- and b-funds set the same fee, and both types make positive profits.

Proposition 4 For some parameter values, there exist pooling equilibria in which both types set $e_{p}>\frac{c}{R_{b}}$.

Given the complexity of the conditions that define both the pooling and the separating equilibria, we have not attempted to ascertain which type of equilibrium holds for a greater range of parameter values or investors' beliefs. As we did above for the case of separating equilibria, we have numerically found the range of values of $c$ and $\gamma$ consistent with the existence of a pooling equilibria for the case in which $p=\frac{1}{2}$. Figures ??-?? show that pooling equilibria can also exist for reasonable parameter values.

Inspection of propositions 3 and 4 seems to indicate that quality is not rewarded in the market for mutual funds, since g-funds charge fees that are lower or equal than those charged by b-funds. Quality is, however, rewarded by higher profits: at any equilibrium, g-funds obtain higher profits than b-funds. At a separating equilibrium, the no-imitation constraint (NIg), ensures that $w_{g}^{U}\left(R_{g} e_{g}-c\right) \geq w_{b}^{U}\left(R_{g} e_{b}-c\right)$, which, since $R_{g}>R_{b}$, implies that $w_{g}^{U}\left(R_{g} e_{g}-c\right)>w_{b}^{U}\left(R_{b} e_{b}-c\right)$. At a pooling equilibrium, all funds charge the same fee, $e_{p}$ and get the same market share. The fact that $R_{g}>R_{b}$ immediately implies that $\frac{1}{N}\left(R_{g} e_{p}-c\right)>\frac{1}{N}\left(R_{b} e_{p}-c\right)$.

The model in this section departs from the benchmark complete information model in two dimensions, and it is instructive to see how each of these dimensions contributes to the existence of separating equilibria like the ones described in Proposition 3. First, the existence of unsophisticated investors allows b-funds to survive while setting fees that differ from those of g-funds. As we saw in the previous section, this would not be possible if all investors held correct beliefs in equilibrium and could move their money freely. In this respect, our model resembles models of price dispersion based on the presence of search costs (like Salop and Stiglitz, 1977), where impediments to search allow firms charging higher prices to obtain positive market shares. Second, the presence of asymmetric information limits the competitive pressure on g-funds. If sophisticated investors could observe fund 
quality, competition among g-funds would drive $e_{g}$ down to $\frac{c}{R_{g}}$, but such a situation could not be an equilibrium with unsophisticated investors, because g-funds can set a higher fee, sell to unsophisticated investors and make a positive profit. It should thus be emphasized that the existence of unsophisticated investors alone cannot generate separating equilibria with both fund types active.

In light of Proposition 3, it is worth reevaluating whether our characterization of unsophisticated investors implies that these investors behave in a way that would be considered unreasonable even for investors such as those described by the survey evidence discussed at the beginning of this section. A possible concern is that:

$$
e_{U}>\frac{R_{b}-1}{R_{b}}
$$

where $\frac{R_{b}-1}{R_{b}}$ is the fee that guarantees the reservation return when investing with a b-fund. Therefore, at a separating equilibrium, some unsophisticated investors (those paired with b-funds) would do better by investing in the reservation asset. We do not think that this requires too much unsophistication from investors for two reasons. First, unsophisticated investors earn an average return at least as high as that of the alternative asset, since a fraction $p$ of unsophisticated investors are paired with g-funds. The average return for unsophisticated investors is:

$$
\begin{aligned}
p\left(1-e_{g}^{*}\right) R_{g} & +(1-p)\left(1-e_{U}\right) R_{b}>p\left(1-e_{U}\right) R_{g}+(1-p)\left(1-e_{U}\right) R_{b}= \\
& =\left(1-e_{U}\right)\left(p R_{g}+(1-p) R_{b}\right)=\left(1-e_{U}\right) \bar{R}=1
\end{aligned}
$$

The second reason is that most studies agree that the average actively managed mutual fund has historically delivered below market returns, at least after expenses and transaction costs are deducted (see Wermers, 2000, for a recent analysis). In this sense, our model would seem to require too much, rather than too little, sophistication from investors.

Another possible concern relates to the assumption that unsophisticated investors do not update their beliefs about funds' quality based on the fees charged by those funds. Given that, in a separating equilibrium, good and bad funds set different fees, one may wonder whether separating equilibria like the ones described above could survive. There are again two reasons why we are not especially worried by this concern. The first reason 
is theoretical. Although we have assumed that $e_{U}$ is the maximum fee that an investor would like to pay for a fund of average quality, the proof of Proposition 3 shows that a separating equilibrium can exist as long as $e_{U}>1-\frac{1}{R_{b}}$, that is, as long as the maximum fee that unsophisticated investors are willing to pay is greater than the maximum fee a sophisticated investor would be willing to pay for a low-quality fund. Therefore, as long as unsophisticated investors do not fully update their beliefs (i.e., if they do not believe that a fund setting $e_{U}$ is bad with probability one), separating equilibria can exist. The second reason is empirical. As we discuss in section 5, the inverse relation between expenses and performance has been extensively documented. In the survey reported by Alexander et al. (1997), however, about 20 percent of respondents believed that mutual funds with higher expenses produced better results, 64.4 percent believed that funds with higher expenses produced average results, and only 15.7 percent of the survey respondents believed that higher expenses led to lower-than-average returns. Since the negative relationship between fees and performance had been already identified by several studies before the survey was conducted, the survey shows that a significant fraction of investors had not optimally updated their beliefs. Further, investors' money, and not just investors' opinion, seems to show that a sizeable proportion of them is not making the right investment choices. As Martin Gruber put it, we see that money remains in funds that can be predicted to do poorly and that, in fact, do perform poorly (Gruber, 1996, p. 807).

\section{Noisy Performance Signals}

Throughout the article, we have assumed that, while fund managers knew their expected performance, the only information available to investors prior to their investment decision was contained in the fees charged by mutual fund managers. If funds differ in their ability to generate returns, however, we should expect past returns to convey some information about fund quality. Therefore, we would like to know if our results are robust to the existence of a noisy signal of fund quality. Further, if past returns were accurate predictors of future performance, the very assumption of asymmetric information could be put into question, so it is important to know to what extent future performance can be predicted on the basis of information about past returns. 
The empirical evidence shows that significant underperformance is a reasonably good predictor of future underperformance. In other words, there seems to exist performance persistence for worst-performing funds. The existence of persistence at the top, however, remains a hotly debated issue. Grinblatt and Titman (1992) and Hendricks, Patel, and Zeckhauser (1993), among others, find that previous years' winners and losers tend to repeat (this is known as the "hot hand" phenomenon). Carhart (1997), however, questions these findings, explaining the perceived persistence of top performers in terms of survivorship bias and the momentum anomaly in the stock market. More recent evidence (see, for instance, Bollen and Busse, 2005), however, shows that there is some performance persistence at the top, although this persistence is short lived (not longer than a quarter).

Two conclusions can be drawn from this evidence. First, information on past returns has some predictive value, although this predictive value is limited. And, second, as evidenced by the lack of consensus in the literature, the problem of predicting future performance on the basis of past returns is very complex and requires advanced financial and quantitative skills. Taken together, these conclusions imply that, for individual investors, past returns will be, at best, a noisy signal of performance. The limited information conveyed by past returns also implies that managers may be better informed than investors. In other words, the observed performance persistence is compatible with the existence of asymmetric information. Moreover, although the fact that fund managers may be better informed than investors does not justify assuming that they will, in fact, be better informed, we believe that one should expect fund managers to have a better assessment than investors about their expected performance. The reason is twofold. First, fund managers are likely to possess more advanced financial skills and better research tools than individual investors. Second, and most importantly, fund managers have access to return-relevant information not available to investors. For instance, managers continuously observe the composition of the portfolio they manage, while investors can only observe the fund's portfolio composition at some pre-specified moments throughout the year. Fund managers also observe each trade they make and the transaction costs associated with each of those trades. Further, managers are likely to have a better idea of their skills, the skills of their staff and the quality of their research tools. In particular, fund managers can assess the accuracy of their own forecasts 
and, thus, assess whether fund results are due to their investment strategy or to luck. Finally, fund managers are better informed than investors about the likelihood of future changes in the fund's staff (in particular, the probability of their own departure from the management team) or investment strategy.

The limited value that past returns have for investors as predictors of future performance justifies, in our view, making the simplifying approximation that there is, in fact, no information available to them other than fund fees. To check the robustness of our results, however, we next extend the model to allow investors to observe a noisy signal of performance before making their investment decision. In the interest of brevity, we do not analyze pooling equilibria and focus strictly on whether the results obtained in the previous section concerning the relationship between fees and fund quality at separating equilibria still hold when there is a noisy signal of performance.

Suppose that, after funds set fees, investors observe a noisy signal $\sigma$ of fund quality, which can take two values, $l$ or $h$ (low or high). Conditional on the fund's type, $\sigma$ is i.i.d. across funds with a probability distribution given by: $\operatorname{Pr}(l \mid b)=\operatorname{Pr}(h \mid g)=\nu>1 / 2$. Therefore,

$$
\begin{gathered}
\operatorname{Pr}(g \mid h)=\frac{p \nu}{p \nu+(1-p)(1-\nu)} \equiv h>p \\
\operatorname{Pr}(g \mid l)=\frac{p(1-\nu)}{p(1-\nu)+(1-p) \nu} \equiv l<p
\end{gathered}
$$

That is, upon observing $h$ the probability of a fund being $g$ is $h>p$, and, upon observing $l$ the probability of a fund being $g$ is $l<p$. The higher $\nu$, the higher $h$ and the lower $l$ and, thus, the higher the precision of the signal.

While sophisticated investors will optimally condition their investment decision on performance signals and fees, the response of unsophisticated investors to the presence of a performance signal is less clear a priori. On the one hand, unsophisticated investors may not respond, or respond too little, to the signal if they do not observe it or underestimate the amount of information carried by it. On the other hand, unsophisticated investors may overreact to the signal if they overestimate its precision. To capture the whole possible range of behavior by unsophisticated investors we assume that the fraction of the wealth of unsophisticated investors that a fund with a high value (low value) of the signal expects 
to obtain is given by a function $f_{h}\left(f_{l}\right)$ of the other funds' signals. By varying this function we can account for any degree of responsiveness to the signal by unsophisticated investors. For example, assuming that $N=2$, if unsophisticated investors do not respond to the signal, then $f_{h}\left(\sigma_{h}\right)=f_{h}\left(\sigma_{l}\right)=f_{l}\left(\sigma_{h}\right)=f_{l}\left(\sigma_{l}\right)=\frac{1}{2}$ (where the argument of the function in each case is the realization of the other fund's signal). If unsophisticated investors' investment choice is fully determined by the signal, then $f_{h}\left(\sigma_{h}\right)=f_{l}\left(\sigma_{l}\right)=\frac{1}{2}, f_{h}\left(\sigma_{l}\right)=1$, and $f_{l}\left(\sigma_{h}\right)=0$.

Independently of the way in which unsophisticated investors respond to the signal, it is still the case that, if there exist separating equilibria, then worse-performing funds charge higher fees. The reason is that, at a separating equilibrium, fees are perfect signals of fund quality, while $\sigma$ is only a noisy signal. Therefore, sophisticated investors will optimally disregard the signal and infer quality from the fee alone. As in previous sections, it follows that if $e_{g}>e_{b}$, then it would be profitable for b-funds to imitate g-funds. Therefore, at any separating equilibrium, $e_{g}<e_{b}$.

To check whether separating equilibria like the ones described in Proposition 3 exist in the presence of a signal of fund quality, suppose first that unsophisticated investors disregard the signal $\sigma$. In this case, it is straightforward to check that the conditions that guarantee existence of a separating equilibrium are exactly identical to the ones derived in the absence of $\sigma$. By the argument in the previous paragraph, the money that a $g$ fund expects to obtain from sophisticated investors at a separating equilibrium is exactly the same as in the absence of the signal, since, at a separating equilibrium, sophisticated investors can infer fund quality from fees and, thus, optimally disregard the information contained in $\sigma$. Further, the money that any fund can expect to obtain from unsophisticated investors is $\frac{\gamma}{N}$, which is again the same as in the absence of the signal. Therefore, the equilibrium conditions are exactly identical to the ones derived in the previous section in the absence of a signal. ${ }^{9}$

To analyze the case in which unsophisticated investors condition their investment decision on the signal, let $\bar{s}_{k}$ denote the money that a fund of type $k$ expects to obtain from sophisticated investors at a separating equilibrium and $\bar{u}_{k}$ the money that it expects to ob-

\footnotetext{
${ }^{9}$ Conditions (Pb, NIb', NIg', NDb, NDg NDb', NDg', and PIg), defined in the appendix.
} 
tain from unsophisticated investors. With these definitions, we can write the no-imitation conditions at a separating equilibrium as follows:

$$
\begin{aligned}
\left(\bar{s}_{g}+\bar{u}_{g}\right)\left(R_{g} e_{g}-c\right) & \geq \bar{u}_{g}\left(R_{g} e_{U}-c\right) \\
\bar{u}_{b}\left(R_{b} e_{U}-c\right) & \geq\left(\bar{s}_{g}+\bar{u}_{b}\right)\left(R_{b} e_{g}-c\right),
\end{aligned}
$$

where the first condition ensures that g-funds do not want to set $e_{U}$, and the second one ensures that b-funds do not want to pass as g-funds. In both conditions, $\bar{s}_{b}=0$, since $e_{U}>\frac{R_{b}-1}{R_{b}}$. Note now that if $P(h \mid g)=\nu>1-\nu=\operatorname{Pr}(h \mid b)$, then $\bar{u}_{g}>\bar{u}_{b}$, since a fund with $\sigma=h$ will obtain more money from unsophisticated investors in expectation than a fund with $\sigma=l$, and g-funds are more likely to have a high signal.

To fully characterize a separating equilibrium, we need to check the two no-imitation conditions above, participation constraints for b-funds and sophisticated investors, and constraints that ensure that funds do not want to deviate to a fee that is not played in equilibrium (that is, a fee other than $e_{g}$ or $e_{U}$ ). These conditions are analogous to the ones derived in the absence of a signal, so we do not rewrite them here. Figures ??-?? display the range of parameter values for which separating equilibria exist for the case $N=2$ and for different values of $\nu, f_{l}$ and $f_{h} \cdot{ }^{10}$ Figure ?? displays the range of values of $c$ and $\gamma$ for which separating equilibria exist when the signal is only slightly informative about the fund's type. In particular, $\nu$ is chosen to be 0.55 . In each figure, we consider three different cases. First, unsophisticated investors ignore the signal, that is, $f_{h}\left(\sigma_{h}\right)=$ $f_{l}\left(\sigma_{l}\right)=f_{h}\left(\sigma_{l}\right)=f_{l}\left(\sigma_{h}\right)=0.5$. In this case, represented by the thick solid line, separating equilibria are identical to the ones in the absence of a signal (since unsophisticated investors are equally likely to invest with either fund). Second, unsophisticated investors are more likely to invest in a fund with high signal if the other fund has low signal. In particular, the thin solid line represents the parameter set compatible with equilibrium when $f_{h}\left(\sigma_{l}\right)=$ $0.8>0.2=f_{l}\left(\sigma_{h}\right)$. Finally (dashed lines), we consider the case in which, if the funds have different signals, unsophisticated investors invest only in the fund with a high signal: $f_{h}\left(\sigma_{l}\right)=1>0=f_{l}\left(\sigma_{h}\right)$. As one could have expected, the range of parameters for which

\footnotetext{
${ }^{10}$ Note that, in the figures, $R_{b}<1$. This assumption greatly simplifies the computation of the equilibrium conditions and is empirically accurate: sophisticated investors would never invest with bad actively managed funds if they knew their quality. We would be glad to provide the program used to derived the figures upon request.
} 
a separating equilibrium exists shrinks as unsophisticated investors become more likely to invest with funds with a high value of the signal and as the precision of the signal increases, although the reduction is not severe.

Figures ?? and ?? show what happens as we increase the precision of the signal to $\nu=0.7$ and $\nu=0.9$, respectively. ${ }^{11}$ The figures show that separating equilibria still exist for reasonable parameter values in the limit, that is, as the signal becomes extremely precise, even if the investment decision of unsophisticated investors is completely determined by the signal. We can, therefore, conclude that the results derived in the previous section are largely robust to the presence of a noisy signal of performance. It should be noted that if $\nu=0.50$, so that the signal is not truly informative, then separating equilibria would be identical to those derived in the absence of a signal, independently of the degree to which unsophisticated investors are affected by the signal.

It is worth noting that one could, alternatively, assume that $\sigma$ is observed by funds and investors before funds set their fees. This alternative assumption would allow us to model not just how investors react to noisy performance information, but also how funds strategically respond to information about their own and other funds' performance. The problem with this assumption is that if the signals became public before funds set fees, a fund's decision would have to be made contingent not only on its quality and the value of its signal, but also on the complete profile of other funds' signals, which greatly complicates the analysis. Further, fund expenses are empirically much more persistent than performance, and recent evidence shows that the fees charged for the management of a given fund are only rarely changed (Kuhnen, 2004). This evidence suggests that not much is lost, and much is won in terms of tractability, by assuming that fees are set prior to observing the performance signal.

\footnotetext{
${ }^{11}$ Given the empirical literature on performance persistence, $\nu=0.55$ is a plausible value for the precision of the signal and $\nu=0.7$ can be considered as an upper bound for this precision. The value $\nu=0.9$ is analyzed as a limiting case.
} 


\section{Evidence on the Relationship between Performance and Fees}

\subsection{Mutual Fund Fee Structure}

In the market for mutual funds, the fees paid by investors take two forms: periodic fees (operating expenses) and one-time fees (loads). ${ }^{12}$ Expenses mostly consist of management fees, but also include 12b-1 (distribution and marketing) fees, custody fees, and administrative fees, as well as operating, legal, and accounting costs. They are computed as a percentage of assets under management-termed the expense ratio-and are deducted on a daily basis from the fund's net assets by the managing company. Fees paid to brokers in the course of the fund's trading activity are not included in the fund's expense ratio.

Loads are generally used to pay distributors, and they differ from operating expenses in that they are paid by the individual investor as a fraction of the amount invested at the time of purchasing fund shares (sales charge on purchases) or redeeming fund shares (deferred sales charge). Since fund returns are typically computed from the fund's net asset value, quoted returns are net-of-expenses, but before loads.

\subsection{Empirical Evidence}

The quality of an actively managed fund is commonly defined as the manager's ability to deliver returns above those that any investor could obtain following a passive strategy, such as investing in an index fund. Differences in managerial quality could translate into differences in after-expense returns if quality were not fully priced. If higher quality were partly priced, that is, if better funds charged higher expenses, differences in after-expense returns would be smaller than differences in fees. On the other hand, if high-quality funds happened to charge lower fees, differences in after-expense returns would be greater than differences in fees. ${ }^{13}$

Elton et al. (1993) divide a sample of U.S. mutual funds available in the 1965-84 period into quintiles by expense ratios and measure average after-expense risk-adjusted

\footnotetext{
${ }^{12}$ Mahoney (2004) provides a review of mutual fund fee practices and regulation. For a more detailed description, we suggest that the reader visit the Online Publications section of the SEC internet site.

${ }^{13}$ If we let $r_{i}$ be the before-expense return of fund $i$ and $e_{i}$ be the expenses charged by this fund, then the after-expense return $\bar{r}_{i}$ is given by $\left(1+\bar{r}_{i}\right)=\left(1-e_{i}\right)\left(1+r_{i}\right)=1+r_{i}-e_{i}-r_{i} e_{i} \approx 1+r_{i}-e_{i}$. Therefore, $\bar{r}_{i}-\bar{r}_{j}=r_{i}-e_{i}-\left(r_{j}-e_{j}\right)=\left(e_{j}-e_{i}\right)+\left(r_{i}-r_{j}\right)$. It follows that if fund $j$ charges a higher fee $\left(e_{j}-e_{i}>0\right)$ and $\bar{r}_{i}-\bar{r}_{j}>0$, then $r_{i}-r_{j}>0$, that is, fund $j$ must have lower before-expense returns.
} 
returns ${ }^{14}$ for funds in each quintile. They find that funds with higher expense ratios perform significantly worse, and that performance differences between funds in the best and the worst quintiles exceed differences in fees, which suggests that funds with higher expenses exhibit lower before-expense returns. Put differently, low-quality funds seem to be more expensive. Similarly, Gruber (1996) studies cross-section differences in afterfee performance in the 1985-94 period. ${ }^{15}$ When ranking funds according to performance, Gruber (1996) finds that differences in expenses are negatively and significantly correlated with larger differences in performance.

Harless and Peterson (1998) analyze data employed in early performance studies and find that the predictive power of expense ratios with respect to performance also extends to the 1954-64 period. They conclude that "all the studies show that funds with the lowest expense ratios tend to perform best, and funds with highest expense ratios tend to perform worst."

Carhart (1997) proposes a different measure of performance. ${ }^{16}$ When regressing this performance measure on expense ratios, he estimates that in the 1962-93 period funds with annual expenses of 100 basis points above the average had on average 154 basis points below mean after-expense performance. Again, the effect of fees is to amplify rather than mitigate differences in before-expense performance.

Finally, Chevalier and Ellison (1999), using a measure of performance similar to Carhart's (1997), report that manager and fund characteristics-such as the portfolio turnover ratio and $\log$ of assets-contribute to explaining differences in performance in the 1988-95 period. When controlling for these variables, they provide estimates of the effect on after-expense performance of a 100 basis point reduction in expense ratios that range from 152 to 225 basis points.

Put together, the empirical evidence implies that superior management is not priced

\footnotetext{
${ }^{14}$ In particular, they measure performance as the intercept term from the regression of annual returns on three indexes, tracking the evolution of stocks in the S\&P 500 index, non-S\&P stocks, and bonds. This measure of performance can be interpreted as the value added by the fund manager with respect to a passive strategy.

${ }^{15}$ Gruber (1996) analyzes three alternative proxies for performance: (i) the fund's average return relative to the market; (ii) the fund's average return in excess of the fund's expected return according to the Capital Asset Pricing Model; and (iii) the fund's average excess return according to a four-index model.

${ }^{16}$ Carhart (1997) employs a four-factor model which captures the fund's exposure to sources of undiversifiable risk.
} 
through higher expense ratios. On the contrary, the effect of expenses on after-expense performance (even after controlling for funds' observable characteristics) is more than oneto-one, implying that low-quality funds charge higher fees. Price and quality thus appear to be inversely related in the market for actively managed mutual funds.

\section{Conclusion}

In this paper, we have shown that, in the mutual fund industry, better-quality funds should not be expected to charge higher prices. Moreover, investors' limited ability to evaluate fund quality may lead to equilibria in which worse-performing funds charge higher fees. We thus obtain a form of inverse price differentiation which is consistent with existing evidence on mutual fund performance.

The fundamental role played by mutual funds and the current demands for regulatory action call for further analysis of the mutual fund industry. Our model suggests several directions for future research. In particular, a richer model of mutual fund competition should capture a wider set of strategic choices by mutual fund managers. For instance, while we have taken fund quality as exogenous, mutual fund management companies may, to some extent, set the quality of the funds they offer through their choice of managers or their expenditure in market analysis.

Also, funds might try to differentiate themselves through their marketing decisions. One could expect that old-enough funds with a good performance record could advertise that performance record to attract unsophisticated investors. Moreover, the theoretical literature in industrial organization offers additional rationales for the existence of informative advertising (for a recent review of the literature, see Bagwell, 2005). In the context of the mutual fund sector, however, our conjecture is that advertising could well be associated with lower rather than with higher quality. In particular, it may not be difficult for lowquality funds to advertise on the basis of some measure of performance (such as short term risk-unadjusted returns). Moreover, it is not clear that it is in the interest of better funds to advertise. The reason is that while unsophisticated investors are likely to respond to advertising, sophisticated investors can be expected to be insensitive to advertising, since they can obtain and process publicly available information about fund performance. There- 
fore, funds catering only to the unsophisticated segment might want to advertise in order to gain market share in that sector, while better funds might avoid advertising precisely to distinguish themselves from bad funds. Consistently with this reasoning, Gallaher, Kaniel and Starks (2006, table 8) have recently found that mutual funds with better performance do not have larger advertising expenditures, and, for some types of funds, larger advertising expenditures are associated with lower performance.

Although in this paper we have specifically modelled the market for mutual funds, the insights of the model may be generalizable to other markets where quality assessment is costly. The existing empirical evidence on the relationship between quality and price suggests that the correlation between these two variables is typically not strongly positive and that, in a significant number of markets, the correlation is indeed negative (e.g., Caves and Greene, 1996). In our model, the negative correlation between price and quality results from the combination of asymmetric information about product quality and the presence of a subset of unsophisticated investors. Future work may further explore, both theoretically and empirically, how these and other factors affect observed price-quality correlations.

Our results indicate that the complexity associated with the evaluation of fund quality may, on the one hand, weaken competition, leading to high average fees even in the presence of a large pool of competing mutual funds, and, on the other hand, lead to a segmented market in which a fraction of investors pay higher than average fees for underperforming funds. Whether this state of things could be improved by regulation and the optimal form of this regulation are questions that merit further scrutiny. Currently, both the SEC and NASD, the self-regulatory arm of the U.S. securities industry, impose limits on redemption fees and the loads that can be charged to mutual fund investors to pay for brokerage services. Our results open the question as to whether some form of cap on expenses could be beneficial in this context. A less contentious alternative, already having been pursued by the SEC, is to require that funds improve the disclosure of their fees, so as to allow investors to realize the dollar cost of the expenses paid. The SEC, however, has stopped short of requiring funds to periodically disclose to each investor the exact dollar amount of the expenses paid on the grounds that such a requirement would impose large processing costs on mutual fund companies. Given the large potential costs that a poor understanding 
of the impact of fees on returns has for unsophisticated investors, our model would suggest reevaluating this cost-benefit analysis. Our model also suggests that requiring funds to disclose the level of fees charged by the fund compared to the average or median fees in the corresponding investment category-information that is already voluntarily disclosed by some mutual fund management companies-could greatly contribute to prevent funds from overcharging unsophisticated investors. 


\section{Appendix.}

\section{Proof of Proposition 3.}

First, notice that $e_{b} \leq \frac{R_{b}-1}{R_{b}}$ cannot be an equilibrium fee, as slightly undercutting such $e_{b}$ would guarantee the deviating b-fund all the sophisticated market in case there are no g-funds and would only marginally reduce its profits in all other cases. This implies that, in equilibrium $e_{b}>\frac{R_{b}-1}{R_{b}}$, so a necessary condition for the existence of a separating equilibrium is $e_{U}>\frac{R_{b}-1}{R_{b}}$, which is satisfied by $e_{U}=1-\frac{1}{\bar{R}}$.

Next, notice that, if a separating equilibrium exists, $e_{b}^{*}=e_{U}$. Any $e_{b} \in\left(\frac{R_{b}-1}{R_{b}}, e_{U}\right)$ cannot be an equilibrium, as such a fee will not convince sophisticated investors to invest with a b-fund even if all funds turn out to be of type $\mathrm{b}$, and $e_{U}$ yields greater profits from the unsophisticated investors. Since $e_{b} \leq \frac{R_{b}-1}{R_{b}}$ cannot be an equilibrium fee either, the only possible equilibrium fee for b-funds is $e_{b}^{*}=e_{U}>\frac{c}{R_{b}}$.

Given $e_{b}=e_{U}>\frac{R_{b}-1}{R_{b}}, w_{b}^{U}=\frac{\gamma}{N}$, so the participation constraint for b-funds and the no-imitation constraints read:

$$
\begin{aligned}
& \frac{\gamma}{N}\left(R_{b} e_{U}-c\right) \geq 0 \\
& \frac{\gamma}{N}\left(R_{b} e_{U}-c\right) \geq w_{g}^{U}\left(R_{b} e_{g}-c\right) \\
& w_{g}^{U}\left(R_{g} e_{g}-c\right) \geq \frac{\gamma}{N}\left(R_{g} e_{U}-c\right),
\end{aligned}
$$

where $w_{g}^{U} \in\left(\frac{\gamma}{N}, \frac{\gamma}{N}+(1-\gamma)\right]$.

The no-imitation constraints can be rewritten:

$$
\begin{aligned}
& e_{g} \geq \frac{\gamma}{N w_{g}^{U}} e_{U}+\left(1-\frac{\gamma}{N w_{g}^{U}}\right) \frac{c}{R_{g}}=\alpha e_{U}+(1-\alpha) \frac{c}{R_{g}} \\
& e_{g} \leq \frac{\gamma}{N w_{g}^{U}} e_{U}+\left(1-\frac{\gamma}{N w_{g}^{U}}\right) \frac{c}{R_{b}}=\alpha e_{U}+(1-\alpha) \frac{c}{R_{b}}
\end{aligned}
$$

where $\alpha \equiv \frac{\gamma}{N w_{g}^{U}}$. Since $w_{g}^{U}>\frac{\gamma}{N}, \alpha<1$. Therefore, the incentive constraint (NIb') implies that $e_{g}<e_{U}$, which proves part 3 .

Let us assume that sophisticated investors' beliefs are such that if a fund sets $e \in$ $\left[\frac{c}{R_{g}}, \frac{c}{R_{b}}\right.$ ), it will be believed to be a g-fund, while for any $e \geq \frac{c}{R_{b}}$ (other than g-funds' equilibrium fee if $\left.e_{g} \geq \frac{c}{R_{b}}\right)$, it will be believed to be a b-fund. This implies that $e_{g} \in\left(\frac{c}{R_{g}}, \frac{c}{R_{b}}\right]$ cannot be an equilibrium fee. Since $e_{g}$ needs to be strictly greater than $\frac{c}{R_{g}}$, the only possible equilibrium fees satisfy $e_{g}>\frac{c}{R_{b}}$. 
Let $m_{b}$ be the minimum fee that would make it profitable for a b-fund to deviate if it captures the whole sophisticated market:

$$
\begin{gathered}
\left(\frac{\gamma}{N}+(1-\gamma)\right)\left(R_{b} m_{b}-c\right)=\frac{\gamma}{N}\left(R_{b} e_{U}-c\right), \text { i.e., } \\
m_{b}=\frac{\gamma}{N-\gamma(N-1)} e_{U}+\left(1-\frac{\gamma}{N-\gamma(N-1)}\right) \frac{c}{R_{b}}= \\
=\lambda e_{U}+(1-\lambda) \frac{c}{R_{b}},
\end{gathered}
$$

where $\lambda \equiv \frac{\gamma}{N-\gamma(N-1)}<1$.

Similarly, let $m_{g}$ be the minimum fee that would make it profitable for a g-fund to deviate if it captures the whole sophisticated market:

$$
\left(\frac{\gamma}{N}+(1-\gamma)\right)\left(R_{g} m_{g}-c\right)=w_{g}^{U}\left(R_{g} e_{g}-c\right)
$$

Rearranging:

$$
\begin{aligned}
m_{g} & =\frac{N w_{g}^{U}}{\gamma+(1-\gamma) N} e_{g}+\left(1-\frac{N w_{g}^{U}}{\gamma+(1-\gamma) N}\right) \frac{c}{R_{g}} \\
& =\phi e_{g}+(1-\phi) \frac{c}{R_{g}}
\end{aligned}
$$

where $\phi \equiv \frac{N w_{g}^{U}}{\gamma+(1-\gamma) N}<1$.

Let $M_{b}\left(M_{g}\right)$ be the be the minimum fee that would make it profitable for a b-fund (g-fund) to deviate and capture the whole sophisticated market only when there are no g-funds:

$$
\begin{aligned}
\frac{\gamma}{N}\left(R_{b} e_{U}-c\right) & =\left(R_{b} M_{b}-c\right)\left(\frac{\gamma}{N}+(1-p)^{N-1}(1-\gamma)\right) \\
w_{g}^{U}\left(R_{g} e_{g}-c\right) & =\left(R_{g} M_{g}-c\right)\left(\frac{\gamma}{N}+(1-p)^{N-1}(1-\gamma)\right)
\end{aligned}
$$

Notice that these inequalities imply $m_{g}<M_{g}$ and $m_{b}<M_{b}$.

If $e_{g}>\frac{c}{R_{b}}$, the maximum fee that a deviating fund can charge while guaranteeing the whole sophisticated-investor market with probability one is $d \equiv \max \left\{\hat{e}, \frac{c}{R_{b}}\right\}$, where

$$
\hat{e} \equiv \frac{e_{g} R_{g}-\left(R_{g}-R_{b}\right)}{R_{b}}
$$

is defined by $\left(1-e_{g}\right) R_{g}=(1-\hat{e}) R_{b}$.

Similarly, the maximum fee that a deviating fund can charge while guaranteeing the whole sophisticated-investor market in case all other funds are of type b is

$$
D \equiv \max \left\{\frac{c}{R_{b}}, \frac{R_{b}-1}{R_{b}}\right\}
$$


Therefore, the no-deviation conditions for b- and g-funds are, respectively:

$$
\begin{gathered}
m_{b} \geq d \\
m_{g} \geq d \\
M_{g} \geq D \\
M_{b} \geq D
\end{gathered}
$$

Finally, $e_{g}$ has to be such that sophisticated investors are willing to invest with g-funds:

$$
e_{g} \leq \frac{R_{g}-1}{R_{g}},
$$

which will immediately hold since $e_{U} \leq \frac{R_{g}-1}{R_{g}}$ and $e_{g}<e_{U}$.

An equilibrium will exist if all the inequality conditions (Pb, NIb', NIg', NDb, NDg NDb', NDg', and PIg) are satisfied simultaneously.

Given the relatively large number of parameters $\left(R_{g}, R_{b}, p, N, c, \gamma\right)$ and inequalities, we do not fully characterize the set of equilibria. Instead, we next show existence numerically. Figures ??-?? show parameter regions for which this type of equilibrium exists.

\section{Proof of Proposition 4.}

Let $e_{p}$ be the pooling fee and $\bar{R}=p R_{g}+(1-p) R_{b}$ denote the unconditional expectation of gross returns. We will assume that sophisticated investors' beliefs are such that, if a fund sets $e \in\left[\frac{c}{R_{g}}, \frac{c}{R_{b}}\right)$, it will be believed to be a g-fund, while for any $e \geq \frac{c}{R_{b}}$ other than the equilibrium fee, it will be believed to be a b-fund.

For sophisticated investors to be willing to buy from a fund of unknown type:

$$
e_{p} \leq 1-\frac{1}{\bar{R}}
$$

i.e., $e_{p} \leq e_{U}$.

For b-funds to be willing to participate:

$$
e_{p} \geq \frac{c}{R_{b}}
$$

For a fund of type $k$ not to be willing to deviate and serve the unsophisticated investor segment only:

$$
\begin{gathered}
\frac{1}{N}\left(e_{p} R_{k}-c\right) \geq \frac{\gamma}{N}\left(e_{U} R_{k}-c\right), \text { or } \\
e_{p} \geq \gamma e_{U}+(1-\gamma) \frac{c}{R_{k}}
\end{gathered}
$$


Since $R_{g}>R_{b}$, it suffices to require

$$
e_{p} \geq \gamma e_{U}+(1-\gamma) \frac{c}{R_{b}}
$$

which implies PCbp, since, by Assumption 3, $e_{U}>\frac{c}{R_{b}}$.

Let $m_{g}$ and $m_{b}$ be the minimum fees that would make it profitable for a g- or a b-fund, respectively, to deviate.

$$
\begin{aligned}
& \left((1-\gamma)+\frac{\gamma}{N}\right)\left(m_{g} R_{g}-c\right)=\frac{1}{N}\left(e_{p} R_{g}-c\right) \\
& \left((1-\gamma)+\frac{\gamma}{N}\right)\left(m_{b} R_{b}-c\right)=\frac{1}{N}\left(e_{p} R_{b}-c\right)
\end{aligned}
$$

If we let

$$
N^{*} \equiv N(1-\gamma)+\gamma
$$

it follows that:

$$
m_{g}=\frac{1}{N^{*}} e_{p}+\left(1-\frac{1}{N^{*}}\right) \frac{c}{R_{g}}<\frac{1}{N^{*}} e_{p}+\left(1-\frac{1}{N^{*}}\right) \frac{c}{R_{b}}=m_{b},
$$

Now, let $\underline{e}$ be the maximum fee that would convince investors to shift to a fund believed to be bad, that is:

$$
\begin{array}{r}
(1-\underline{e}) R_{b}=\left(1-e_{p}\right) \bar{R}, \\
\text { or } \\
\underline{e}=1-\left(1-e_{p}\right) \frac{\bar{R}}{R_{b}}
\end{array}
$$

Therefore, if a fund deviates and sets $d \equiv \max \left\{\underline{e}, \frac{c}{R_{b}}\right\}$, it will capture the whole sophisticated market, so, for a g-fund not to be willing to deviate, it has to be the case that:

$$
m_{g} \geq d
$$

which also implies that b-funds do not want deviate because $m_{b}>m_{g}$.

Case 1: $d=\underline{e}$. Let us first look at the case in which $d=\underline{e}$, that is:

$$
\begin{array}{r}
1-\left(1-e_{p}\right) \frac{\bar{R}}{R_{b}} \geq \frac{c}{R_{b}}, \text { or } \\
e_{p} \geq \tilde{e} \equiv \frac{\bar{R}-\left(R_{b}-c\right)}{\bar{R}}
\end{array}
$$


In this case the no-deviation condition for g-funds reads:

$$
\begin{gathered}
m_{g}=\frac{1}{N^{*}} e_{p}+\left(1-\frac{1}{N^{*}}\right) \frac{c}{R_{g}} \geq 1-\left(1-e_{p}\right) \frac{\bar{R}}{R_{b}}=\underline{e}, \text { or } \\
e_{p} \leq \frac{N^{*} R_{g}\left(\bar{R}-R_{b}\right)+\left(N^{*}-1\right) R_{b} c}{R_{g}\left(N^{*} \bar{R}-R_{b}\right)}
\end{gathered}
$$

For an equilibrium of this sort to exist, thus, conditions (PCip), (NDu), (19) and (20) have to hold simultaneously.

First note that, given Assumption 2, (19) implies (NDu) for $\gamma$ low enough. Inspection of the conditions also shows that for (PCip) and (19) to hold simultaneously it is necessary that

$$
R_{b}-c>1
$$

If this condition holds, then it only rests to check that (19) and (20) can hold simultaneously. This requires:

$$
\frac{\bar{R}-\left(R_{b}-c\right)}{\bar{R}}<\frac{N^{*} R_{g}\left(\bar{R}-R_{b}\right)+\left(N^{*}-1\right) R_{b} c}{R_{g}\left(N^{*} \bar{R}-R_{b}\right)}
$$

After some algebra, this condition can be shown to be equivalent to:

$$
R_{b}<p\left(R_{b}+R_{g}\left(\frac{R_{b}-N^{*} c}{\left(N^{*}-1\right) c}\right)\right)
$$

Therefore, at least for $\gamma$ low enough (so that we do not have to worry about condition $\mathrm{NDu}$ ), if $R_{b}>N^{*} c$, a pooling equilibrium will exist for high enough values of $p$. Note, in particular, that existence does not require that $\gamma>0$, so that this type of equilibrium would also exist in the absence of unsophisticated investors.

Case 2: $d=\frac{c}{R_{b}}$. In equilibrium, $d=\frac{c}{R_{b}}$ if and only if:

$$
e_{p} \leq \frac{\bar{R}-\left(R_{b}-c\right)}{\bar{R}}
$$

For g-funds not to deviate, we need $m_{g} \geq d=\frac{c}{R_{b}}$, i.e.,

$$
e_{p} \geq \frac{c}{R_{g}}+N^{*} c \frac{R_{g}-R_{b}}{R_{g} R_{b}}
$$

Thus, for an equilibrium of this sort to exist, conditions (PCip), (NDu), (24), and (25) must hold. We need to consider two cases: 
1. $R_{b}-c>1$. In this case, condition (PCip) is implied by (24) and conditions (NDu) and (24) are always compatible for $\gamma$ low enough since:

$$
\begin{aligned}
\frac{\bar{R}-\left(R_{b}-c\right)}{\bar{R}}>\frac{c}{R_{b}} \Leftrightarrow \bar{R} R_{b}-R_{b}\left(R_{b}-c\right)>c \bar{R} \Leftrightarrow \\
\bar{R}\left(R_{b}-c\right)-R_{b}\left(R_{b}-c\right)>0 \Leftrightarrow \bar{R}-R_{b}>0,
\end{aligned}
$$

which is always true.

It rests to check that conditions (24) and (25) are compatible as well. This will happen if and only if:

$$
\frac{c}{R_{g}}+N^{*} c \frac{R_{g}-R_{b}}{R_{g} R_{b}}<\frac{\bar{R}-\left(R_{b}-c\right)}{\bar{R}}
$$

Rearranging this expression leads to inequality (23), so the same conditions as above guarantee existence of this type of equilibrium.

2. $R_{b}-c<1$. Now, condition (24) is implied by (PCip). The latter condition will be consistent with (25) only if:

$$
1-\frac{1}{\bar{R}}>\frac{c}{R_{g}}\left(1+\frac{N^{*} R_{g}}{R_{b}}-N^{*}\right)
$$

For fixed $R_{b}$ and $R_{g}$, the supremum of the left-hand side is $1-\frac{1}{R_{g}}$ (when $p \rightarrow 1$ ). The infimum of the right-hand side is $\frac{R_{b}-1}{R_{g}}\left(1+\frac{N^{*} R_{g}}{R_{b}}-N^{*}\right)$ if $R_{b}>1$ (when $c \rightarrow 1-R_{b}$ ), and 0 if $R_{b}<1$ (when $c \rightarrow 0$ ). In the latter case, the above condition will hold. If $R_{b}>1$, we must have:

$$
\frac{R_{g}-1}{R_{g}}>\frac{R_{b}-1}{R_{g}}\left(1+\frac{N^{*} R_{g}}{R_{b}}-N^{*}\right)
$$

Rearranging,

$$
\begin{gathered}
\left(R_{g}-1\right) R_{b}>\left(R_{b}-1\right)\left(R_{b}+N^{*} R_{g}-N^{*} R_{b}\right) \Leftrightarrow \\
R_{b}<\frac{N^{*}}{N^{*}-1}
\end{gathered}
$$

Therefore, if (30) holds and $\frac{R_{g}-1}{R_{g}}>\frac{c}{R_{b}}$, then there are pooling equilibria with $R_{b}-c<1$. 


\section{References}

[1] Alexander, G. J., J. D. Jones, and P. J. Nigro, 1997. Mutual fund shareholders: Characteristics, investor knowledge, and sources of information. Office of the Comptroller of the Currency, E\&PA Working Paper 97-13.

[2] Bagwell, K., 2005. The economic analysis of advertising. In Armstrong, M. and R. Porter (eds.), forthcoming. Handbook of Industrial Organization, Vol. 3, NorthHolland: Amsterdam.

[3] Bagwell, K. and M. H. Riordan, 1991. High and declining prices signal product quality. American Economic Review 81, 224-239.

[4] Barber, B. M., O. Terrance and Z. Lu, 2005. Out of sight, out of mind: the effects of expenses on mutual fund flows. Journal of Business 78, 2095-2120.

[5] Berk, J. B. and R. C. Green, 2004. Mutual fund flows and performance in rational markets. Journal of Political Economy 112, 1269-1295.

[6] Bhattacharya, S. and P. Pfleiderer, 1985. Delegated portfolio management. Journal of Economic Theory 36, 1-25.

[7] Bollen, Nicolas P. B., and Jeffrey A. Busse, 2005. Short-term persistence in mutual fund performance. Review of Financial Studies 18, 569-597.

[8] Capon, N., G. Fitzimmons, and R. Prince, 1996. An individual level analysis of the mutual fund investment decision. Journal of Financial Services Research 10, 59-82.

[9] Carhart, M., 1997. On persistence in mutual fund performance. Journal of Finance 52, $57-82$.

[10] Caves, R. E. and D. P. Greene, 1996. Brands' quality levels, prices, and advertising outlays: empirical evidence on signals and information costs. International Journal of Industrial Organization 14, 29-52.

[11] Chevalier, J. and G. Ellison, 1999. Are some mutual fund managers better than others? Cross-sectional patterns in behavior and performance. Journal of Finance 54, 875-899. 
[12] Christoffersen, S. and D. Musto, 2002. Demand curves and the pricing of money management. Review of Financial Studies 15, 1499-1524.

[13] Cox, J. D. and J. Payne, J., 2005. Mutual fund expense disclosures: a behavioral perspective. Washington University Law Quarterly 84, 907-938.

[14] Das, S. R. and R. K. Sundaram, 2002. Fee speech: Signaling, risk-sharing, and the impact of fee structures on investor welfare. Review of Financial Studies 15, 1465-1497.

[15] Dwyer, P., A. Borrus and L. Young, 2003. Breach of trust. Business Week, December 15.

[16] The Economist, 2004. Low fidelity, September 23.

[17] Elton, E. J., M. J. Gruber, S. Das, H. Matthew, 1993. Efficiency with costly information: a reinterpretation of evidence from managed portfolios. Review of Financial Studies $6,1-22$.

[18] Fluet, C. and P. G. Garella, 2002. Advertising and prices as signals of quality in a regime of price rivalry. International Journal of Industrial Organization 20, 907-930.

[19] Gabaix, X. and D. Laibson, 2003. Some industrial organization with boundedly rational consumers. Working paper, Harvard University.

[20] General Accounting Office, 2000. Mutual fund fees. Additional disclosure could encourage price competition (GAO/GGD-00-126). Washington D.C.: General Accounting Office.

[21] Gallaher, S., R. Kaniel, and L. Starks, 2006. Madison Avenue meets Wall Street: mutual fund families, competition and advertising. Working paper, Duke UniversityFuqua School of Business.

[22] Grinblatt, M. and S. Titman, 1992, The persistence of mutual fund performance. Journal of Finance 47(5), 1977-1984.

[23] Gruber, M., 1996. Another puzzle: The growth in actively managed mutual funds. Journal of Finance 52, 783-810. 
[24] Harless, D. W., S. P. Peterson, 1998. Investor behavior and the persistence of poorlyperforming mutual funds. Journal of Economic Behavior and Organization 37, 257-276.

[25] Hendricks, D., J. Patel, and R. Zeckhauser, 1993. Hot hands in mutual funds: short run persistence of relative performance, 1974-1988. Journal of Finance 48, 93-130.

[26] Hertzendorf, M. N. and P. B. Overgaard, 2001. Price competition and advertising signals: Signaling by competing senders. Journal of Economics and Management Strategy 10, 621-662.

[27] Hortacsu, A. and C. Syverson, 2004. Product differentiation, search costs, and the welfare effects of entry: a case study of S\&P 500 index funds. Quarterly Journal of Economics 119, 403-456.

[28] Investment Company Institute, 2004. Mutual Fund Factbook, 43rd Edition. Washington, D.C.: Investment Company Institute.

[29] Kuhnen, Camelia M., 2004. Dynamic contracting in the mutual fund industry. Working paper, Stanford Graduate School of Business.

[30] Mahoney, P. G., 2004. Manager-investor conflicts in mutual funds, Journal of Economic Perspectives 18, 161-182.

[31] Metrick, A. and R. Zeckhauser, 1999. Price versus quantity: Market clearing mechanisms when sellers differ in quality. Journal of Risk and Uncertainty 17, 175-190.

[32] Nanda, V., M. P. Narayanan and V. A. Warther, 2000. Liquidity, investment ability, and mutual fund structure. Journal of Financial Economics, 57, 417-443.

[33] Palomino, F. and A. Prat, 2003. Risk taking and optimal contracts for money managers. RAND Journal of Economics 34, 113-137.

[34] Salop, S. and J.E. Stiglitz, 1977. Bargains and ripoffs: A model of monopolistically competitive price dispersion. Review of Economic Studies 44, 493-510. 
[35] Securities and Exchange Commission, 2000. Report on mutual fund fees and expenses. Washington, D.C.: Securities and Exchange Commission, Division of Investment Management.

[36] Securities and Exchange Commission, 2004. Disclosure regarding portfolio managers of registered management investment companies, 69 Federal Register, August 27.

[37] Schmalensee, R., 1978. A model of advertising and market structure. Journal of Political Economy 86, 485-503.

[38] Shaked A. and J. Sutton, 1982. Relaxing price competition through product differentiation. Review of Economic Studies 49, 3-13.

[39] Slovic, P., 1972. From Shakespeare to Simon: Speculations and some evidence about mans ability to process information. Oregon Research Institute Monograph, 12.

[40] Wermers, R., 2000. Mutual fund performance: An empirical decomposition into stockpicking talent, style, transactions costs, and expenses. Journal of Finance 55, 16551695.

[41] Wilcox, R. T., 2003. Bargain hunting or star gazing? investors' preferences for stock mutual funds. Journal of Business 76, 645-663. 